Flash Report

\title{
Why don't we believe non-native speakers? The influence of accent on credibility
}

\author{
Shiri Lev-Ari*, Boaz Keysar \\ The University of Chicago, Chicago, IL, USA
}

\section{A R T I C L E I N F O}

Article history:

Received 9 April 2010

Revised 25 May 2010

Available online 25 June 2010

\section{Keywords:}

Foreign accent

Fluency

Attribution

Credibility

\begin{abstract}
A B S T R A C T
Non-native speech is harder to understand than native speech. We demonstrate that this "processing difficulty" causes non-native speakers to sound less credible. People judged trivia statements such as "Ants don't sleep" as less true when spoken by a non-native than a native speaker. When people were made aware of the source of their difficulty they were able to correct when the accent was mild but not when it was heavy. This effect was not due to stereotypes of prejudice against foreigners because it occurred even though speakers were merely reciting statements provided by a native speaker. Such reduction of credibility may have an insidious impact on millions of people, who routinely communicate in a language which is not their native tongue.
\end{abstract}

(C) 2010 Elsevier Inc. All rights reserved.
People constantly learn new things from a variety of sources. One of the most important and prevalent sources of information is other people (Soll, 1999; Yaniv, 2004). Most people do not know how many hours a night an ant typically sleeps, but if someone tells them that ants don't sleep, they may believe it, even if that person is not a zoologist. But people also doubt and routinely evaluate new information (Ferguson \& Zayas, 2009). Such judgments of credibility could depend on how reasonable the information sounds, how credible the source appears how the person says it (e.g., Miller \& Hewgill, 1964), how much cognitive capacity is available (e.g., Gilbert, 1991 ) and so on. Here we focus on how speakers' accent impacts their credibility. Specifically, we investigate the impact of accented speech on the believability of the message.

Most non-native speakers have an accent, and it could cause them to seem less credible for two main reasons: (1) The accent serves as a signal, and (2) the accent makes the speech harder to process. There is some evidence for the first reason, but not for the second. Native speakers are very sensitive to foreign accented speech, and are quick to use it as a signal that the speaker is an out-group member. This conjures up stereotypes about outsiders, which promote prejudice that could impact the credibility of the speaker (e.g., Dixon, Mahoney \& Cocks, 2002). When a foreign accent acts as a signal, it is the prejudice, not the accent per-se that impacts the credibility of the speaker. In contrast, the difficulty of understanding the speaker is inherent to the accent itself. We propose that people believe non-native speakers less, simply because they are harder to understand.

In general, the ease of processing stimuli, or "processing fluency," affects the way stimuli are judged (e.g., Oppenheimer, 2008; Schwarz, 2004). Stimuli that are easier to process are perceived, among other

\footnotetext{
* Corresponding author.

E-mail address: shiri@uchicago.edu (S. Lev-Ari).
}

things, as more familiar (Whittlesea, Jacoby, \& Girard, 1990), more pleasant (Reber, Schwarz, \& Winkielman, 2004; Whittlesea, 1993; Zajonc, 1968), visually clearer (Whittlesea et al., 1990), longer and more recent (Whittlesea, 1993), louder (Jacoby, Allan, Collins, \& Larwill, 1988), less risky (Song \& Schwarz, 2009), and more truthful (Reber \& Schwarz, 1999). For example, people judge "Woes unite foes" as a more accurate description of the impact of troubles on adversaries than "Woes unite enemies," because the rhyming of woes and foes increases processing fluency (McGlone \& Tofighbakhsh, 2000). Similarly, people judge the statement "Osorno is in Chile" as more true when the color of the font makes it easier to read (Reber \& Schwarz, 1999).

The basis for the attribution of processing ease to truthfulness seems to be learned correlations between the two. True statements are more likely to be repeated than erroneous ones, and the repetition facilitates processing. Indeed, exposing people to the reverse correlation reverses the direction of the attribution (Schwarz, Sanna, Skurnik, \& Yoon, 2007; Unkelbach, 2007). Given that accented speech is harder to process (Munro \& Derwing, 1995), we tested whether processing difficulty makes it harder to believe non-native speakers.

To test our idea, it is important to show that the difficulty of understanding accented speech has a unique effect on perceived credibility which cannot be attributed to stereotypes about non-native speakers. A good test case for this would be a speaker who is simply delivering a message from a native speaker. If people find the message less believable when the messenger has an accent, then the judged credibility is impacted by the processing fluency of the speech, not by prejudice.

We tested the impact of accent on truth judgments in two experiments. In the first experiment we asked people to judge the truthfulness of trivia statements written by the experimenter but recited by either native or non-native speakers of English. The non-native speakers had either a mild or a heavy accent, and they had one of five different native tongues. In Experiment 2 we tested whether awareness reduces the impact of accent on perceived truthfulness. People are often 
unaware of the source of their processing difficulty, but once they realize it, they are less likely to misattribute it (Whittlesea et al., 1990). Therefore, awareness of the source of the difficulty may help reduce the misattribution of accent difficulty to truthfulness.

\section{Experiment 1}

Experiment 1 tested whether trivia statements sound less true when said with a foreign accent than without. We also tested whether this is true for both mild and heavy accents. Because awareness of the source of the difficulty could eliminate the influence of ease of processing, and because heavy accents are prominent, listeners might be able to correctly attribute the source of the difficulty when accent is heavy than when it is mild. Therefore, we used three types of accent: native, mild and heavy.

\section{Method}

\section{Participants}

Thirty native speakers of American English participated in the experiment. We excluded two participants because they guessed the manipulation.

\section{Materials and design}

Three native English speakers, three non-native speakers of English with a mild accent, and thee with a heavy accent recorded 45 trivia statements such as $A$ giraffe can go without water longer than a camel can. Each speaker recorded all 45 statements. We classified the level of accent according to the judgments of four native English speakers. They listened to all speakers reciting a sample of the sentences. For each sentence, they marked the difficulty of each of the speakers on a line whose poles were labeled extremely easy and extremely difficult. For five of the speakers, judges agreed $97 \%$ of the time that three of them had a milder accent than the other two. We replaced the sixth speaker because of lack of agreement, and two judges agreed $100 \%$ of the time that the new speaker is harder to understand than the mildly accented speakers. The native tongues of the mildly accented speakers were Polish, Turkish and Austrian-German, and the native tongues of the heavily accented speakers were Korean, Turkish and Italian.

Each participant listened to all 45 statements, 15 by the native speakers, 15 by the speakers with the mild accent and 15 by the speakers with the heavy accent. Statements and speakers were counterbalanced, and statements were presented in two mirror orders across participants. To reduce suspicion and the prominence of accent, each participant heard 17 filler and "example" statements read by two additional native speakers. Half of the statements in each version were true.

\section{Procedure}

Participants enrolled in the experiment, which was ostensibly about intuition in knowledge assessment. We made sure the participants understood that the speakers were only reciting what the experimenter wrote. First, the experimenter clarified that the speakers were not expressing their own knowledge but only reading aloud statements that she provided. Most importantly, participants first served as "speakers," and recorded five trivia statements, supposedly for future participants. This allowed them to fully understand that the speakers were just reciting statements provided by the experimenter. The experimenter then informed participants of the truth-value of each statement they recited, helping them appreciate that the speakers learned this only after reciting. Finally, the experimenter explained that they would then listen to past participants who also recorded such statements. This demonstrated that the linguistic and cultural background of the speakers was irrelevant for the veracity of the statements.

Participants listened to each statement and indicated its veracity on a $14 \mathrm{~cm}$ line, with one pole labeled definitely false and the other definitely true. We measured the distance from the false pole in centimeters, so a higher number indicates a more truthful statement. The experiment began with two example sentences, followed by the 60 trivia statements. In addition, participants indicated if they had known for a fact that a statement was true or false and specified the source of this information (e.g., class, TV). Participants also indicated if they could not understand what the speaker said.

At the end of the experiment participants completed a questionnaire about their previous linguistic experience, including exposure to accents and the similarity of those accents to the accents of the speakers in the experiment.

\section{Results and discussion}

As predicted, accented speech was rated as less truthful than native speech (see Fig. 1). We analyzed listeners' truth judgments with a mixed model. The basic model included Subjects and Items as random variables, and Knowledge (Not known, Known-False, Known-True) as a fixed variable. We then examined whether Accent influenced truth judgment. As predicted, adding Accent (Native, Mild, Heavy) improved the model $\left(\chi^{2}=10.3, p<0.01\right)$ and showed that Accent negatively influenced truth judgments. Contrasts revealed that participants perceived statements by speakers with a mild $(M=6.95, S D=0.26)$ and heavy accent $(M=6.84$, $\mathrm{SD}=0.27)$ as less true than those by native speakers $(M=7.59$, $\mathrm{SD}=0.36 ; t=-2.74$ and $t=-2.77$, respectively). Statements with mild and heavy accent did not differ from each other $(t=-0.11)$.

Participants reported knowing for a fact the veracity of $6.1 \%$ of the statements. We evaluated whether this knowledge prevented misattribution of processing difficulty to truthfulness. We added the interaction of Accent with Knowledge to the model, but this did not improve the model $\left(\chi^{2}=\sim 0, p>0.9\right.$ ). The misattribution of the difficulty, then, occurs with unfamiliar and familiar content, showing that knowledge does not protect from the influence of processing difficulty (See also, Fazio, \& Marsh, 2009).

In general, then, even when speakers just deliver information from others, people perceive this information as less truthful when the speaker has an accent. They misattribute the difficulty of understanding the speech to the truthfulness of the statement.

We raised the possibility that heaviness of accent might cue participants to the influence of the difficulty of processing the speech, but the judged veracity of heavy and mildly accented statements did not differ. This suggests either that a heavy accent is not a sufficient cue, or that participants tried to correct the effect of heavy accent, yet corrected insufficiently. Experiment 2 further examined the role of awareness.

\section{Experiment 2}

Experiment 2 tested whether highlighting the difficulty of processing accented speech more directly would lead listeners to correct for

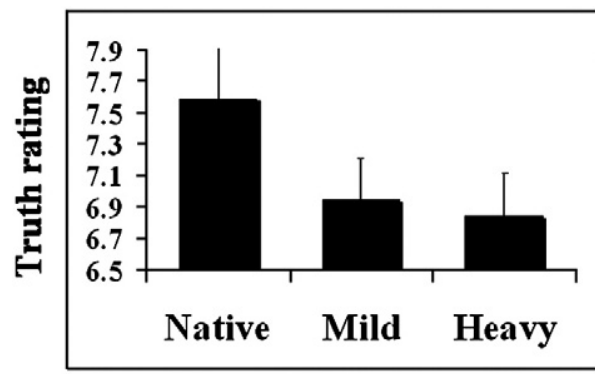

\section{Accent}

Fig. 1. Truth ratings as a function of accent in Experiment 1. The $y$ axis indicates distance in $\mathrm{cm}$ from the Definitely False pole of the scale, so higher numbers indicate higher perceived truth. 
the difficulty. To evaluate this, we told participants that the experiment tests whether the difficulty of understanding speech influences truth judgments, and asked them to rate the difficulty of understanding each speaker.

Method

Participants

Twenty-seven native speakers of English participated in this experiment. ${ }^{1}$

Stimuli and design

The stimuli were identical to those in Experiment 1. Unlike the first experiment, we blocked the presentation by speaker in order to allow participants to rate the difficulty of understanding each speaker.

\section{Procedure}

The procedure was identical to that of Experiment 1, except (1) We told participants that "The experiment is about the effect of the difficulty of understanding speakers' speech on the likelihood that their statements would be believed." (2) After rating the five statements by each speaker, participants rated the difficulty of understanding that speaker on a continuous scale ranging from Very easy to Very difficult.

\section{Results and discussion}

Participants attempted to counteract the impact of processing difficulty, but were only partially successful. As Fig. 2 shows, while participants rated statements with mild accent just as truthful as statements by native speakers, they rated heavily accented statements as less truthful than either. We analyzed the data with a mixed model with Items and Subjects as random variables and knowledge (KnownFalse, Not known, Known-True) as a fixed variable. Next we added Accent (Native, Mild, Heavy) as a fixed variable. This improved the model $\left(\chi^{2}=11.345, p<0.01\right)$. Accent was negatively associated with truthrating. Contrasts showed that statements were rated as significantly less true when said with a heavy accent $(\mathrm{M}=6.9, \mathrm{SE}=0.22)$ than a mild $(\mathrm{M}=7.52, \mathrm{SE}=0.22 ; t=2.94)$ or a native accent $(\mathrm{M}=7.47, \mathrm{SE}=0.34$; $t=2.93$ ). Truth rating did not differ between mild and native accents $(t=0.02)$. Experiments 1 and 2 used slightly different procedures and therefore cannot be directly compared, yet Experiment 2 shows that when listeners are aware of the difficulty of understanding the speakers, they no longer perceive mildly accented statements as less true.

Next we replaced Accent with Difficulty Rating as a fixed variable to see whether it similarly predicted truth judgment. This model was also better than the basic model $\left(\chi^{2}=5.85, p<0.02\right)$ and revealed that statements seemed less credible the harder it was to understand the speaker. Difficulty Rating did not interact with Knowledge, as adding an interaction to the model did not improve it $\left(\chi^{2}=1.6, p>0.4\right)$. We could not test whether Accent interacts with Knowledge because none of the mildly accented statements were known to be false by participants.

\section{General discussion}

We showed that people perceive statements as less truthful when spoken by non-native speakers. When people listen to accented speech, the difficulty they encounter reduces "processing fluency." But instead of perceiving the statements as more difficult to understand, they perceive them as less truthful. Consequently, non-native speakers who have an accent are seen as less credible. This is true even when prejudice

\footnotetext{
${ }^{1}$ We also ran another group of subjects with different instructions that were irrelevant to the focus of this report. Details are available upon request.
}

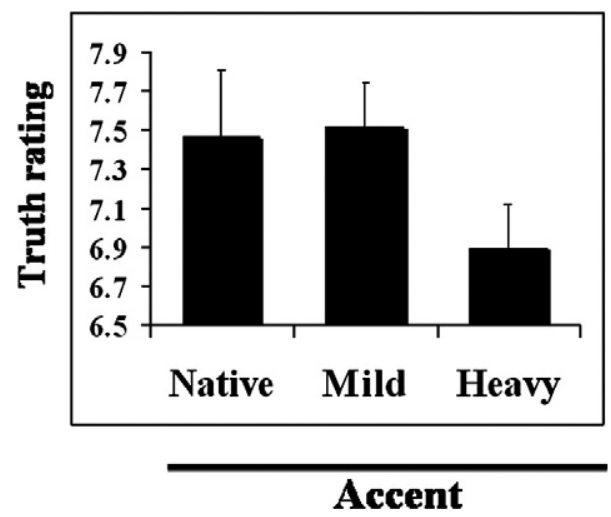

Fig. 2. Truth ratings as a function of accent in Experiment 2. The $y$ axis indicates distance in $\mathrm{cm}$ from the Definitely False pole of the scale, so higher numbers indicate higher perceived truth.

against foreigners could not play a role, when the speaker is playing the role of a messenger, conveying information from a native speaker.

When people are aware that the difficulty of processing accented speech could impact their judgment of credibility, they attempt to avoid this misattribution. With forewarning they succeeded when speakers had a mild accent, but were unable to undo the impact of difficulty when speakers had a heavy accent. Ironically, in natural circumstances heavy accent is more likely than mild accent to cue people about the impact of processing difficulty, but listeners are unable to undo the impact of heavy accent even when informed.

One limitation of the experiments is that the native tongue of the speakers was different in the mild and the heavy accent conditions. Yet the different patterns of results in the two experiments suggest that participants were not relying on prejudice or an affective reaction to the speech. In post-experiment questionnaires, participants could not even identify the native tongues of the speakers. In the real world, however, speakers are often more than messengers, and stereotypes are likely to play a later role. We are assuming that such stereotypes would not alter the attribution of fluency to truthfulness, but that they would come into play later in the process, augmenting the effect of processing fluency when negative, and mitigating it when positive.

These results have important implications for how people perceive non-native speakers of a language, particularly as mobility increases in the modern world, leading millions of people to be non-native speakers of the language they use daily. Accent might reduce the credibility of non-native job seekers, eyewitnesses, reporters or news anchors. As we showed, such insidious impact of accent is even apparent when the non-native speaker is merely a messenger. Most likely, neither the native nor the non-native speakers are aware of this, making the difficulty of understanding accented speech an ever present reason for perceiving non-native speakers as less credible.

\section{Acknowledgment}

We thank Linda Ginzel for commenting on a draft, and Chelsey Norman and Joy Heafner for technical assistance. The research was funded by National Science Foundation grant BCS-0849034.

\section{References}

Dixon, J. A., Mahoney, B., \& Cocks, R. (2002). Accents of guilt? Effects of regional accent, 'race' and crime type on attributions of guilt. Journal of Language and Social Psychology, 21, 162-168.

Fazio, K., \& Marsh, E.J. (2009, November) Prior knowledge does not protect against illusory truth effects. Paper presented at the 50th Annual Meeting of the Psychonomic Society, Boston, MA. 
Ferguson, M., \& Zayas, V. (2009). Automatic evaluation. Current Directions in Psychological Science, 18(6), 362-366.

Gilbert, D. T. (1991). How mental systems believe. American Psychologist, 46, $107-119$.

Jacoby, L. L., Allan, L. G., Collins, J. C., \& Larwill, L. K. (1988). Memory influences subjective experience: Noise judgments. Journal of Experimental Psychology: Learning, Memory, and Cognition, 14, 240-247.

McGlone, M. S., \& Tofighbakhsh, J. (2000). Birds of a feather flock conjointly(?):Rhyme as reason in aphorisms. Psychological Science, 11, 424-428.

Miller, G. R., \& Hewgill, M. A. (1964). The effect of variations in nonfluency on audience ratings of source credibility. Quarterly Journal of Speech, 50(1), 36-44.

Munro, M. J., \& Derwing, T. M. (1995). Processing time, accent, and comprehensibility in the perception of native and foreign-accented speech. Language and Speech, 38 , 289-306.

Oppenheimer, D. M. (2008). The secret life of fluency. Trends in Cognitive Science, 12(6), $237-241$.

Reber, R., \& Schwarz, N. (1999). Effects of perceptual fluency on judgments of truth. Consciousness and Cognition, 8, 338-342.

Reber, R., Schwarz, N., \& Winkielman, P. (2004). Processing fluency and aesthetic pleasure: Is beauty in the perceiver's processing experience? Personality and Social Psychology Review, 8(4), 364-382.
Schwarz, N. (2004). Meta-cognitive experiences in consumer judgment and decision making. Journal of Consumer Psychology, 14, 332-348.

Soll, J. B. (1999). Intuitive theories of information: Beliefs about the value of redundancy. Cognitive Psychology, 38, 317-346.

Song, H., \& Schwarz, N. (2009). If it's difficult-to-pronounce, it must be risky: Fluency, familiarity, and risk perception. Psychological Science, 20, 135-138.

Schwarz, N., Sanna, L. J., Skurnik, I., \& Yoon, C. (2007). Metacognitive experiences and the intricacies of setting people straight: Implications for debiasing and public information campaigns. Advances in Experimental Social Psychology, 39, 127-161.

Unkelbach, C. (2007). Reversing the truth effect: Learning the interpretation of processing fluency in judgments of truth. Journal of Experimental Psychology: Learning, Memory, and Cognition, 33, 219-230.

Whittlesea, B. W. A. (1993). Illusions of familiarity. Journal of Experimental Psychology: Learning, Memory, and Cognition, 19, 1235-1253.

Whittlesea, B. W. A., Jacoby, L. L., \& Girard, K. (1990). Illusions of immediate memory: Evidence of an attributional basis for feelings of familiarity and perceptual quality. Journal of Memory and Language, 29, 716-732.

Yaniv, I. (2004). The benefit of additional opinions. Current Directions in Psychological Science, 13, 75-78.

Zajonc, R. B. (1968). Attitudinal effects of mere exposure. Journal of Personality and Social Psychology. Monograph Supplement, 9, 1-27. 